\title{
IVERSIDADE DE PLANTAS EM QUINTAIS QUILOMBOLAS, CONHECIMENTO LOCAL SOBRE USO E CULTIVO DE PIMENTAS na Amazônia Oriental, Brasil
}

\author{
luciano Araujo Pereira
}

Universidade do Estado do Amapá (UEAP), Av. Presidente Vargas, 650, Centro, Macapá, AP, Brasil. CEP: 68.900-000. E-mail: laraujopereira@gmail.com

\section{JACKSON RODRIGO de LIMA-BARBOSA}

Universidade do Estado do Amapá (UEAP), Av. Presidente Vargas, 650, Centro, Macapá, AP, Brasil. CEP: 68.900-000. E-mail: jbarbosa_87@hotmail.com

\section{Mara Zélia de Almeida}

Universidade Federal da Bahia (UFBA), Faculdade de Farmácia, Departamento do Medicamento, Rua Barão de Geremoabo, S/N, Campus de Ondina, Ondina, Salvador, BA, Brasil. CEP: 40.170-290. E-mail: marazelia@yahoo.com.br

\section{Elsie Franklin Guimarães}

Instituto de Pesquisas Jardim Botânico do Rio de Janeiro, Rua Pacheco Leão, no 915, Rio de Janeiro, Brasil. CEP: 22.460-030. Conselho Nacional de Pesquisa (CNPq).

E-mail: eguimar@jbrj.gov.br

Resumo: Quintais florestais são áreas ao redor das casas, usadas de forma consorciada, combinando espécies arbóreas lenhosas com cultivos agrícolas e/ou animais. Sua principal função é produzir alimentos para o consumo familiar. O objetivo deste estudo foi verificar a diversidade e o conhecimento sobre o uso e cultivo de plantas em quintais florestais, com destaque às pimentas no estado do Amapá. A pesquisa foi realizada por meio de entrevistas semiestruturadas com 16 especialistas em pimentas em seus respectivos quintais, utilizando a técnica turnê-guiada em quatro localidades da Área de Proteção Ambiental do Rio Curiaú. O material coletado foi processado através do método usual em taxonomia e a diversidade dos quintais verificada pelo Índice de Shannon-Wiener. Foram registrados 5.141 indivíduos, em 64 famílias, 130 gêneros e 155 espécies; nove táxons de pimentas em 21 nomes populares pertencentes às famílias Solanaceae e Piperaceae. Curiaú de Fora e Curiaú de Dentro apresentaram maior riqueza e Curiaú de Fora apresentou a maior diversidade de espécies. Os especialistas demonstraram conhecer e usar as espécies cultivadas como medicinal, alimentar, comercial, ritualístico, dentre outros, em especial Capsicum frutescens L. Os quintais florestais apresentam-se como uma estratégia viável para a conservação e manutenção da diversidade local.

Palavras-chave: Conhecimento local, Manejo de pimentas, Pimentas do Amapá, Quintais florestais.

\section{Diversity Of PLANTS IN QUiLOMBOLA HOMEGARDENS, LOCAL KNOWLedge ON THE use AND Cultivation of peppers in the Eastern Amazon, Brazil}

Abstract: Homegardens are areas around the house used to form consortiums, matching hardwood
tree species with agricultural crops and/or animals. Its main function is to produce food for family con-
sumption. The aim of this study was to assess the diversity and knowledge about the use and manage-
ment of forest plants in the homegardens, especially about the peppers in the state of Amapá (Brazil). 
The survey was conducted through semi-structured interviews with 16 experts in their respective homegardens, using the guided-tour in four localities of the Environmental Protection Area of Rio Curiaú. The material was processed through the usual method in taxonomy and diversity of homegardens verified by the Shannon-Wiener Index. We recorded 5141 individuals in 64 families, 130 genera and 155 species. Among 21 popular names of peppers, we found nine taxa belonging to Solanaceae and Piperaceae families. Curiaú de Fora and Curiaú de Dentro showed higher richness and Curiaú de Fora showed the greatest diversity of species. The experts showed the knowledge about the plants and how to use the managed species in areas such as medicinal, food, commercial, ritualistic, among others, in particular Capsicum frutescens $\mathrm{L}$. The homegardens stand as a viable strategy for the conservation and maintenance of local diversity.

Keywords: Local knowledge, peppers management, peppers Amapá, homegardens.

\section{INTRODUÇÃO}

Q uintais florestais são áreas ao redor das casas ou de pequenas propriedades, que se caracterizam pelo seu uso de forma consorciada. São amplamente distribuídos nas regiões tropicais e têm como um dos seus elementos, a satisfação das necessidades locais, uma alternativa ao uso da terra, nas quais se combinam espécies arbóreas lenhosas (frutíferas e/ou madeireiras) com cultivos agrícolas e/ou animais, de forma simultânea ou em sequência temporal e que interagem econômica e ecologicamente (Fernandes \& Nair, 1986; Embrapa, 2007). Segundo Florentino, Araujo \& Albuquerque (2007) apresentam recursos contínuos e várias funções, sendo a principal a produção de alimentos para o consumo da família.

A distribuição das espécies nos quintais é determinada por fatores socioeconômicos, ambientais, hábitos alimentares e pelas demandas do mercado (Fernandes \& Nair, 1986). Na região amazônica são sistemas antigos, que ao longo do tempo vem se constituindo num saber ecológico construído por comunidades indígenas e ribeirinhas, mostrando-se sustentável do ponto de vista biológico, de valor importante para produzir alimentos, além de outros produtos para o uso familiar.

A Amazônia é o maior bioma brasileiro e ocupa cerca de 49,3\% do território nacional (IBGE, 2004). Apresenta a maior biodiversidade do planeta, incluindo a diversidade genética, de espécies e de ecossistemas (Silva, Rylands \& Fonseca, 2005) sendo influenciada tanto por ação antrópica (Clement et al., 2001; WinklerPrins, 2002), quanto por fatores ambientais como a variação do clima, ciclo hidrológico, relevo e elevada umidade, que em parte contribuíram na formação do grande mosaico de ecossistemas (e.g. floresta de terra firme, floresta de várzea, enclaves de cerrado, campinaranas) existentes nesse bioma (Silva \& Rebellato, 2004).

No Amapá é comum a prática de uso pela população de espécies vegetais na forma extrativista e agroextrativista para fins alimentar, ornamental, medicinal e/ou ritualístico (Pereira et al.,
2007), principalmente por especialistas locais, que são pessoas detentoras de um alto conhecimento principalmente em relação ao uso e manejo de plantas medicinais e alimentícias (Silva, 2002).

Nesse contexto, está o uso de espécies denominadas popularmente de pimentas que, geralmente, são adicionadas como condimentos aos pratos típicos da culinária local, medicinais, ritualísticos, dentre outros.

O presente estudo objetiva conhecer a diversidade de plantas cultivadas em quintais, com destaque para o grupo das pimentas, ocorrentes em quatro localidades de uma comunidade quilombola e busca responder às seguintes questões: Qual a diversidade de espécies vegetais úteis nos quintais estudados? Quais espécies locais são conhecidas, usadas e cultivadas como pimentas nos quintais? Qual a importância do uso dessas pimentas no contexto socioeconômico, cultural e medicinal nas unidades familiares estudadas? Existe apenas um único responsável pelo cultivo de pimentas nas unidades familiares e quais técnicas de cultivo são utilizadas nesses quintais?

\section{MATERIAL e MÉtodos}

\section{ÁREA DE ESTUdo}

A Área de Proteção Ambiental (APA) do Rio Curiaú foi criada pela Lei Estadual n. ${ }^{0}$ 0431, de 15 de setembro de 1998 (Amapá, 1998), situada cerca de $11 \mathrm{~km}$ do centro da cidade de Macapá, capital do Amapá. Os seus limites são a cidade de Macapá, ao Sul; o rio Amazonas, a Leste; a vila de Campina Grande do Curiaú, ao Norte e a Rodovia BR-156, a Oeste (Brito \& Drummond, 2007).

Segundo Silva (2002), a APA do Rio Curiaú possui cerca de 1500 pessoas que detém um elevado conhecimento sobre uso e cultivo de plantas medicinais e alimentícias, é composta de seis localidades: Curiaú de Dentro, Curiaú de Fora, 
Extrema, São Francisco da Casa Grande, Mocambo e Curralinho; apenas as três primeiras citadas foram certificadas e reconhecidas como remanescentes de quilombo pelo Título de Reconhecimento no 01/99, emitido pela Fundação Cultural Palmares (FCP), em 25 de novembro de 1999 (Brito \& Drummond, 2007).
A pesquisa foi realizada nas localidades onde foram identificados 16 especialistas em pimentas: Curiaú de Fora $\left(00^{\circ} 08^{\prime} 05,6^{\prime \prime} \mathrm{N}, 51^{\circ} 06^{\prime} 40,9^{\prime \prime} \mathrm{W}\right)$, Curiaú de Dentro $\left(00^{\circ} 08^{\prime} 05,6^{\prime \prime} \mathrm{N}, 51^{\circ} 03^{\prime} 40,7^{\prime \prime} \mathrm{W}\right)$, São Francisco da Casa Grande $\left(00^{\circ} 11^{\prime} 05,5^{\prime \prime} \mathrm{N}\right.$, $\left.51^{\circ} 00^{\prime} 20,6^{\prime \prime} \mathrm{W}\right)$ e Curralinho $\left(00^{\circ} 07^{\prime} 22,9^{\prime \prime} \mathrm{N}\right.$, $\left.51^{\circ} 06^{\prime} 48,9^{\prime \prime} \mathrm{W}\right)$,(Fig. 1).
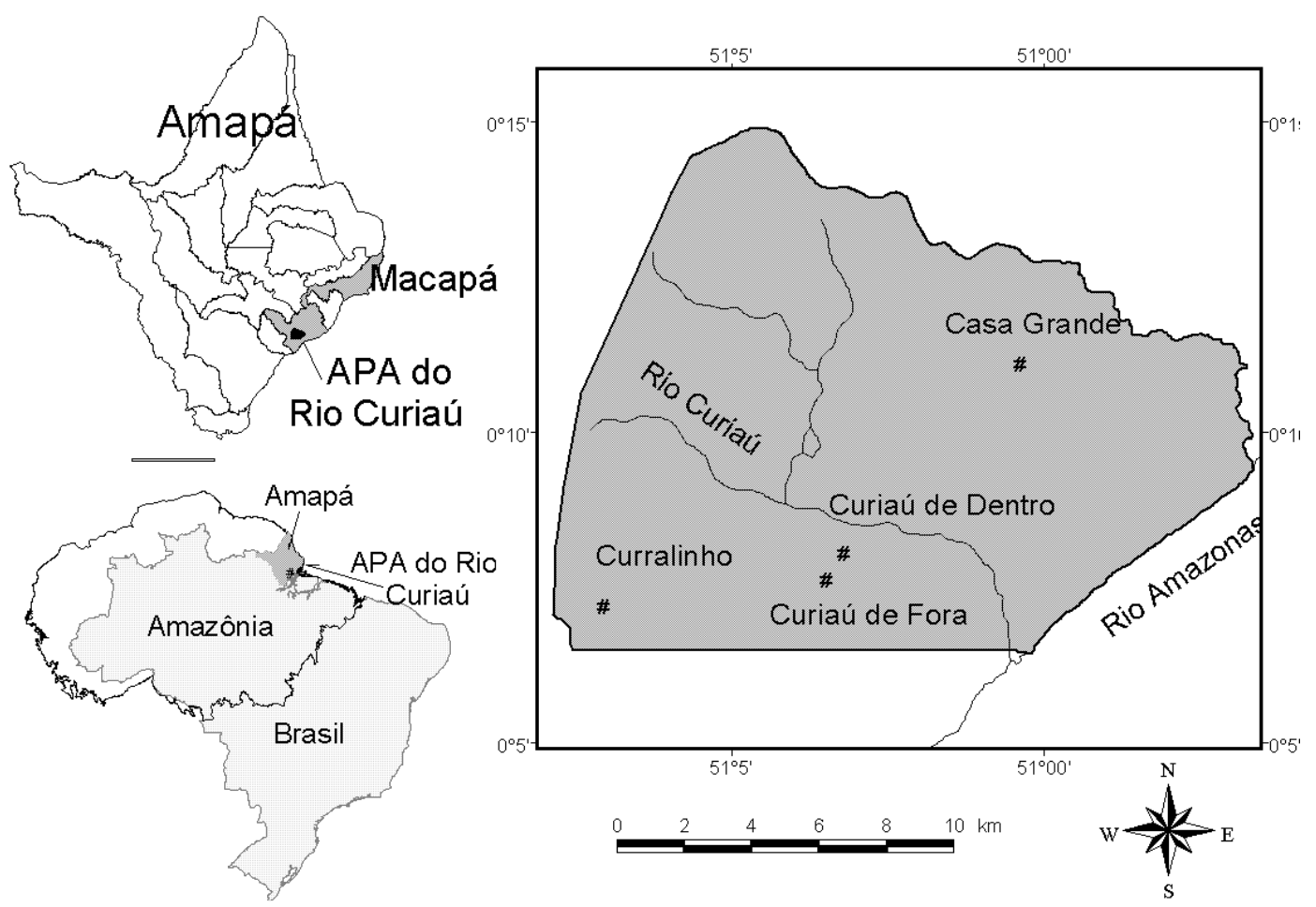

Fig. 1. Localização das áreas estudadas na APA do Rio Curiaú; Macapá; Amapá

Curiaú de Fora foi o local onde se originou o antigo quilombo do Curiaú, enquanto Curiaú de Dentro, distante $2 \mathrm{~km}$ de Curiaú de Fora, tem sua origem devido ao crescimento da população quilombola, com características socioambientais similares. São Francisco da Casa Grande, distante de Curiaú de Dentro 8 km, localiza-se às margens da Rodovia do Curiáu e possui o menor número de moradores. Curralinho, a localidade mais distante de todas as outras, encontra-se a $15 \mathrm{~km}$ por terra de Curiaú de Fora com acesso pelas rodovias do Curiaú e BR 156, muito embora, no período chuvoso seja possível a travessia de barco pelo lago do Rio Curiaú, o que facilita o contato entre os parentes e a cultura ancestral.

\section{Características DA ÁREA DE ESTUdo}

A principal fonte de renda da população é a agricultura, porém, parte dos moradores conta com a ajuda do governo com recebimento da bol- sa família, trabalha em atividades temporárias ou comerciais (bares) do complexo balneário do lago Curiaú, principalmente, no período considerado verão (julho a dezembro). As quatro localidades estudadas dispõem de uma igreja católica, uma escola de ensino fundamental e uma sede da associação de moradores. A localidade de Curiaú de Dentro dispõe também de um templo da igreja Assembléia de Deus, um posto de saúde, um posto policial e um museu que conta a história do quilombo. As propriedades dos moradores, em sua maioria, estão situadas às margens do lago ou da rodovia estadual AP 70 (Rodovia do Curiaú). Possui estrutura física muito peculiar ao local, isto é, as unidades estão divididas em lotes de aproximadamente $20 \times 50 \mathrm{~m}$ e as residências localizadas sempre na parte da frente das propriedades, algumas divididas por cercas que são intercaladas por vias na parte posterior do quintal, onde se desenvolve o cultivo consorciado de plantas perenes, não raro, penetrando e confundindo-se com a vegetação da floresta do entorno. As moradias são de alvenaria ou de tábua 
e todas são servidas de rede de telefonia móvel e fixa, além de telefones públicos, energia elétrica, água encanada e coleta de lixo, não havendo, no entanto, serviço de tratamento de esgoto.

\section{Coleta de dados}

A pesquisa foi realizada no período de 2007 a 2009 nos quintais florestais de 16 especialistas locais. A escolha dos mesmos ocorreu após entrevista efetuada com um dos líderes comunitários da APA, que devido ao seu amplo conhecimento sobre os moradores, indicou alguns que cultivavam pimentas. Em seguida, foi utilizado o método bola-de-neve (Bailey, 1982), em 16 entrevistas estruturadas e semiestruturadas, com oito mulheres e oito homens remanescentes de quilombo, cujas idades variaram entre 46 e 88 anos, registradas com o auxílio de um gravador portátil. Para efetuar as coletas nos quintais, foi utilizada a técnica turnê-guiada (Albuquerque \& Lucena, 2008). Os espécimes foram processados através do método usual em taxonomia (Fidalgo \& Bononi, 1984; Rotta, Carvalho \& Beltrami, 2008; Souza \& Lorenzi, 2008), identificados em literatura especializada. Os nomes científicos e dos autores das espécies foram aferidos nas bases de dados disponíveis na internet Tropicos (2016), The Plant List 2013 (2016), Flora do Brasil 2020 (2016) e APG IV (2016). O material testemunho foi depositado nos Herbários HAMAB e RB, siglas conforme Thiers (2010).

As plantas citadas pelos especialistas foram enquadradas nas categorias de usos: repelente (fumaça para afastar insetos e morcegos); alimentar (temperos, pastas para comer com peixe, molho de tucupi e azeite); comercial (vendas nas feiras, mercados da cidade ou em frente às residências); medicinal (chás das folhas como remédio para doenças do aparelho digestório, espinha no rosto, erisipela, sumo como remédio para brotoeja, cicatrizante, anti-inflamatório, banho contra "mau olhado", infusão de folhas em álcool contra picadas de insetos); ornamental (utilizadas como árvores de natal e nos jardins ao redor das casas); ritualística (benzimento para "descarrego", espantar "maus espíritos", "olho gordo" e "panemeira"), conforme trabalhos etnobotânicos de Miranda \& Hanazaki (2008), Figueiredo, Leitão-Filho \& Begossi (1993), Hanazaki et al. (2000) e Fonseca-Kruel \& Peixoto (2004).

\section{ANÁLISE dos dADOS}

A diversidade florística foi verificada através do Índice de Diversidade de Shannon-Wiener $\left(\mathrm{H}^{\prime}\right)$ e de Simpson (1/D), além do índice de equabilidade de Pielou $\left(\mathrm{J}^{\prime}\right)$, com o intuito de verificar a uniformidade de distribuição dos indivíduos de cada espécie nas amostras (Magurran, 2004). Para calcular os índices foi utilizado o programa Past 2.07 (Hammer, Harper \& Ryan, 2011). Para estimar o número esperado de espécies na amostra, foram realizadas as curvas de rarefações (Colwell, 2005) utilizando-se o número de citações/coleta de cada planta. As curvas de rarefação foram geradas utilizando-se o software BioDiversity Pro (McAleece, Lambshead \& Paterson, 1997). A preferência dos especialistas locais quanto ao uso de pimentas foi verificada a partir do índice de Valor de Uso (Phillips \& Gentry, 1993), seguindo a adaptação efetuada por Rossato, Leitão-Filho \& Begossi (1999), entrevistando uma única vez cada especialista. Para verificar a freqüência relativa das espécies inventariadas, foi utilizada a fórmulas: $F R_{i}=\left(F A_{i}^{p} / i=1 / \Sigma F A_{i}\right) x$ 100 , em que $F R_{i}=$ frequência relativa da i-ésima espécie na comunidade vegetal.

\section{Resultados e discussão}

\section{RIQUEZA E DIVERSIDADE DE PLANTAS NOS QUINTAIS}

No total, foram inventariados 5.141 exemplares, pertencentes a 64 famílias, 130 gêneros e 155 espécies, distribuídas nas quatro localidades estudadas (Tab. 1). Curiaú de Fora com 110 espécies, Curiaú de Dentro (94), São Francisco da Casa Grande (64) e Curralinho (58). Cerca de $32 \%$ das espécies úteis inventariadas são plantas nativas do local, que crescem espontaneamente nos quintais ou são plantadas próximas às residências como Acmella oleracea (L.) R.K. Jansen (jambú), Euterpe oleracea Mart. (açaizeiro), dentre outras (Tab. 1) utilizadas como medicinais e/ ou alimentícias (Florentino, Araujo \& Albuquerque, 2007; Leão, Ferreira \& Jardim, 2007; Ming \& Amaral Junior, 2003). 
Tab. 1. Lista das espécies levantadas nos quintais dos 16 especialistas locais, da APA do Rio Curiaú, com nome popular local e número de coleta. Quantidade de indivíduos/táxons por Localidade (Qipl): Curiaú de Fora (I), Curiaú de Dentro (II), São Francisco da Casa Grande (III) e Curralinho (IV). Em negrito, estão as famílias e os táxons indicados como pimentas pelos especialistas locais

\begin{tabular}{|c|c|c|c|c|c|c|}
\hline \multirow{2}{*}{ FAMÍlIA / NOME CIENTÍfICo } & \multicolumn{4}{|c|}{ QIPL } & \multirow{2}{*}{$\begin{array}{l}\text { NOME POPULAR } \\
\text { LOCAL }\end{array}$} & \multirow{2}{*}{ N. DE COLETA } \\
\hline & $\mathbf{I}$ & II & III & IV & & \\
\hline \multicolumn{7}{|l|}{ ACANTHACEAE } \\
\hline Justicia pectoralis Jacq. & 33 & - & - & - & trevo-cumaru, anador & --- \\
\hline \multicolumn{7}{|l|}{ ASPARAGACEAE } \\
\hline Furcraea foetida (L.) Haw. & - & - & 4 & - & croata & --- \\
\hline \multicolumn{7}{|l|}{ AMARANTHACEAE } \\
\hline Alternanthera sp. & 51 & - & - & - & dipirona & 1793 \\
\hline $\begin{array}{l}\text { Dysphania ambrosioides (L.) Mosyakin \& Cle- } \\
\text { mants }\end{array}$ & 23 & - & 1 & 18 & mastruz & 1682 \\
\hline \multicolumn{7}{|l|}{ AMARYLLIDACEAE } \\
\hline Hippeastrum puniceum (Lam.) Kuntze & 1 & 1 & 1 & - & $\begin{array}{l}\text { cebolinha, açucena flor } \\
\text { branca }\end{array}$ & $1929 / 1749$ \\
\hline \multicolumn{7}{|l|}{ ACARDIACEAE } \\
\hline Anacardium occidentale L. & 23 & 26 & 22 & 5 & caju & 1928 \\
\hline Mangifera indica L. & 24 & 25 & 6 & 12 & manga & 1930 \\
\hline Spondias mombin L. & 3 & 4 & - & 1 & taperebá & 1931 \\
\hline S. purpurea L. & - & 1 & - & - & seriguela & 1932 \\
\hline Tapirira guianensis Aubl. & 1 & - & - & - & tapirira & 1933 \\
\hline \multicolumn{7}{|l|}{ ANNONACEAE } \\
\hline Annona cacans Warm. & - & - & - & 1 & goiaba-da-bahia & 1697 \\
\hline A. muricata L. & 10 & 8 & 15 & 6 & graviola & 1683 \\
\hline A. squamosa L. & 15 & 1 & - & - & ata & 1934 \\
\hline Duguetia lanceolata A. St.-Hil. & - & - & - & 1 & biriba & \\
\hline \multicolumn{7}{|l|}{ APIACEAE } \\
\hline Eryngium foetidum $\mathrm{L}$. & 82 & 3 & 30 & 72 & chicória & $1935^{*}$ \\
\hline \multicolumn{7}{|l|}{ APOCYNACEAE } \\
\hline Hancornia speciosa Gomes & 1 & - & - & - & mangaba & 1976* \\
\hline $\begin{array}{l}\text { Tabernaemontana coronaria (Jacq.) Willd } \\
\text { ARACEAE }\end{array}$ & 7 & - & - & - & cravo-branco & 1763 \\
\hline Caladium bicolor (Aiton) Vent. & 13 & - & 3 & - & $\begin{array}{l}\text { tajá, tamaquaré, unha- } \\
\text {-do-cão }\end{array}$ & $1775 / 1677$ \\
\hline C. humboldtii (Raf.) Schott & 15 & - & - & 2 & tajá brasileirinho & 1977 \\
\hline Colocasia esculenta (L.) Schott. & 5 & 1 & - & - & tajá taioba & --- \\
\hline Dieffenbachia amoena Bull. & 11 & 14 & - & - & Comigo-ninguém-pode & 1960 \\
\hline Philodendron megalophyllum Schott & 1 & - & - & - & cipó-tracuá & 1787 \\
\hline Xanthosoma conspurcatum Schott & - & 1 & - & - & tajá mirim & 1802 \\
\hline \multicolumn{7}{|l|}{ ARECACEAE } \\
\hline ACROCOMIA ACULEATA (JACQ.) LODD. EX MART. & 5 & 2 & 4 & 2 & mucajá & 1978* \\
\hline Astrocaryum aculeatum G. Mey. & 28 & - & 14 & - & tucumã & 1980* \\
\hline Bactris gasipaes Kunth & 17 & 4 & 1 & 1 & pupunha & 1979* \\
\hline Cocos nucifera L. & 26 & 11 & 5 & 12 & coqueiro & 1961 \\
\hline Euterpe oleracea Mart. & 40 & 50 & 15 & - & açaí & 1939* \\
\hline Oenocarpus bacaba Mart. & 1 & 3 & - & - & bacaba & $1948 *$ \\
\hline \multicolumn{7}{|l|}{ ASPHODELACEAE } \\
\hline Aloe vera (L.) Burm. f. & 2 & 2 & 1 & 3 & babosa & 1947 \\
\hline \multicolumn{7}{|l|}{ ASTERACEAE } \\
\hline Acmella oleracea (L.) R.K. Jansen & - & 2 & 22 & - & jambú & $1698^{*}$ \\
\hline Ageratum conyzoides $\mathrm{L}$. & 1 & - & - & - & mata rocha & 1752 \\
\hline $\begin{array}{l}\text { Ayapana triplinervis (M.Vahl) R.M. King \& H. } \\
\text { Rob. }\end{array}$ & 50 & 41 & - & - & japana rosa & 1744 \\
\hline
\end{tabular}


TAB.1 - CONTINUAÇÃo.

\begin{tabular}{|c|c|c|c|c|c|c|}
\hline Mikania glomerata Spreng. & - & - & - & 1 & guaco & 1931 \\
\hline Tagetes minuta L. & - & 1 & - & - & cravo-de-defunto & 1660 \\
\hline $\begin{array}{l}\text { Gymnanthemum amygdalinum (Delile) Sch. } \\
\text { Bip. ex Walp. }\end{array}$ & 1 & 2 & - & 1 & boldo & 1795 \\
\hline \multicolumn{7}{|l|}{ BIGNONIACEAE } \\
\hline Mansoa alliacea (Lam.) A.H.Gentry & 1 & 3 & 2 & - & cipó d'alho & 1959 \\
\hline Fridericia chica (Bonpl.) L.G.Lohmann & 4 & - & 4 & 1 & pariri & $1693 *$ \\
\hline Crescentia cujete L. & 2 & 3 & 8 & 1 & cuiera & 1738* \\
\hline \multicolumn{7}{|l|}{ BIXACEAE } \\
\hline \multicolumn{6}{|l|}{ BORAGINACEAE } & 1981* \\
\hline Heliotropium indicum $\mathrm{L}$ & 1 & - & - & - & fedegoso & 1796* \\
\hline \multicolumn{7}{|l|}{ BRASSICACEAE } \\
\hline Brassica oleracea L. & 1 & - & - & - & couve & 1962 \\
\hline \multicolumn{7}{|l|}{ BROMELIACEAE } \\
\hline Ananas comosus (L.) Merril & 61 & 27 & 21 & 2 & abacaxi & 1938 \\
\hline \multicolumn{7}{|l|}{ BURSERACEAE } \\
\hline \multicolumn{6}{|l|}{ CACTACEAE } & $1741 *$ \\
\hline Nopalea cochenillifera (L.) Salm-Dyck & 2 & - & - & - & cacto & 1951 \\
\hline \multicolumn{7}{|l|}{ CARICACEAE } \\
\hline Carica papaya L. & 40 & 10 & 4 & 9 & mamão & 1982 \\
\hline \multicolumn{7}{|l|}{ CARYOCARACEAE } \\
\hline Caryocar villosum (Aubl.) Pers. & - & 5 & - & - & piquiá & 1733* \\
\hline \multicolumn{7}{|l|}{ CHRYSOBALANACEAE } \\
\hline Licania canescens Benoist & - & 1 & - & - & caripé & 1957* \\
\hline \multicolumn{7}{|l|}{ CONVOLVULACEAE } \\
\hline $\begin{array}{l}\text { Ipomoea batatas (L.) Lam. } \\
\text { COSTACEAE }\end{array}$ & \multicolumn{5}{|c|}{ COSTACEAE } & 1950 \\
\hline $\begin{array}{l}\text { Costus spiralis (Jacq.) Roscoe } \\
\text { CRASSULACEAE }\end{array}$ & 2 & 1 & 15 & 1 & canafiche, canafiste & 1691 \\
\hline Bryophyllum pinnatum (Lam.) Oken & 48 & 9 & 15 & 1 & $\begin{array}{l}\text { escama de pirarucu, pi- } \\
\text { rarucu }\end{array}$ & 1700 \\
\hline \multicolumn{7}{|l|}{ CUCURBITACEAE } \\
\hline Cucurbita pepo L. & - & 10 & 1 & - & jerimum & 1974 \\
\hline \multicolumn{7}{|l|}{ CYPERACEAE } \\
\hline \multicolumn{6}{|l|}{ DILLENIACEAE } & $1789 *$ \\
\hline \multicolumn{6}{|l|}{ DIOSCOREACEAE } & $1792 *$ \\
\hline Dioscorea alata L. & 10 & 1 & - & 1 & cará da terra & 1956 \\
\hline D. bulbifera L. & - & - & 1 & - & cará & 1955 \\
\hline \multicolumn{7}{|l|}{ EUPHORBIACEAE } \\
\hline Codiaeum variegatum (L.) Rumph. ex A. Juss. & 4 & - & - & - & pingo-de-ouro & 1756 \\
\hline Euphorbia tirucalli L & 1 & - & - & - & caranguejo & 1801 \\
\hline Jatropha curcas L. & 8 & 48 & 31 & - & pião roxo, pião caboclo & 1772 \\
\hline J. podagrica Hook. & 1 & - & 2 & - & pião branco & 1773 \\
\hline Manihot esculenta Crantz & 11 & 465 & 2 & 1631 & mandioca & 1675 \\
\hline \multicolumn{6}{|l|}{ FABACEAE } & 1800 \\
\hline Andira inermis (W. Wright)DC. & - & - & 3 & - & alvineira & 1804* \\
\hline Adenanthera pavonina L. & - & - & 1 & - & tento & 1803 \\
\hline Caesalpinia pulcherrima (L.) Sw. & 2 & - & - & - & barba-de-barata & 1755 \\
\hline Enterolobium schomburgkii (Benth.) Benth. & 1 & 7 & 2 & - & esponjeira & 1746* \\
\hline Inga edulis Mart & 2 & 3 & 3 & 1 & ingá cipó & $1694 *$ \\
\hline I. quadrangularis Ducke & 1 & 6 & - & - & ingá-do-mato & 1970* \\
\hline
\end{tabular}


TAB.1 - CONTINUAÇÃO.

\begin{tabular}{|c|c|c|c|c|c|c|}
\hline Senna obtusifolia (L.) H.S. Irwin \& Barneby & 1 & 2 & 2 & - & matapasto & 1734* \\
\hline S. occidentalis (L.) Link & - & 77 & 1 & - & pajé marioba & $1781 *$ \\
\hline Vouacapoua americana Aubl. & - & 1 & - & - & acapu & 1940* \\
\hline \multicolumn{7}{|l|}{ IRIDACEAE } \\
\hline Dietes bicolor (Steud.) Klatt ex Sweet & 1 & - & - & - & dália & 1785 \\
\hline Eleutherine bulbosa (Mill.) Urb. & - & - & - & 1 & marupá & 1984 \\
\hline \multicolumn{7}{|l|}{ LAMIACEAE } \\
\hline Plectranthus amboinicus (Lour.) Spreng. & - & - & - & 1 & hortelã grande & 1969 \\
\hline Gmelina arborea Roxb. ex Sm. & - & - & 2 & - & jamelina & 1805 \\
\hline Mentha piperita L. & 1 & - & - & 2 & hortelã & 1968 \\
\hline Ocimum gratissimum L. & 2 & - & 4 & - & alfavacão & 1774 \\
\hline O. campechianum Mill. & 1 & - & - & - & alfavaquinha & 1943 \\
\hline O. carnosum (Spreng.) Link \& Otto ex Benth. & 6 & 13 & 1 & 7 & esturaque, alfavaca & 1673 \\
\hline Plectranthus ornatus Codd & 1 & - & - & - & boldinho & \\
\hline Rosmarinus officinalis L. & - & 1 & - & - & alecrim & 1942 \\
\hline Vitex agnus-castus L. & 1 & - & - & - & alecrim de angola & 1740 \\
\hline \multicolumn{7}{|l|}{ LAURACEAE } \\
\hline Cinnamomum verum J.Presl & 1 & - & - & 1 & canela & 1681 \\
\hline Mezilaurus itauba (Meisn.) Taub. ex Mez & - & 1 & - & - & mãe de itauba & 1985* \\
\hline Persea americana Mill. & 4 & 14 & 2 & 1 & abacate & 1937 \\
\hline \multicolumn{7}{|l|}{ LECYTHIDACEAE } \\
\hline Bertholletia excelsa Bonpl. & 2 & 1 & - & - & Castanha-do-pará & $1958 *$ \\
\hline Lecythis pisonis Cambess. & - & 2 & - & - & sapucaia & 1986* \\
\hline \multicolumn{7}{|l|}{ LORANTHACEAE } \\
\hline Phthirusa stelis (L.) Kuijt & - & 1 & - & - & erva-de-passarinho & $1742 *$ \\
\hline \multicolumn{7}{|l|}{ LYTHRACEAE } \\
\hline Punica granatum L. & 2 & - & - & - & romã & 1991 \\
\hline \multicolumn{7}{|l|}{ MALPIGHIACEAE } \\
\hline Byrsonima crassifolia (L.) Kunth & 9 & 6 & 3 & 2 & murici & 1684* \\
\hline B. intermedia A. Juss. & - & - & 2 & - & muruci-do-mato & 1987* \\
\hline Malpighia punicifolia L. Malpighia glabra L. & 12 & 9 & 1 & 4 & acerola & 1941 \\
\hline \multicolumn{7}{|l|}{ MALVACEAE } \\
\hline Abelmoschus esculentus (L.) Moench & - & 1 & - & - & quiabo & 1988 \\
\hline Gossypium arboreum L. & 5 & 22 & - & - & algodão & 1944 \\
\hline Hibiscus rosa-sinensis L. & 3 & 2 & - & 1 & $\begin{array}{l}\text { hibisco, brinco-de-prin- } \\
\text { cesa }\end{array}$ & 1751 \\
\hline H. sabdariffa L. & 2 & 1 & - & - & vinagreiro & 1724 \\
\hline $\begin{array}{l}\text { Theobroma grandiflorum (Willd. ex Spreng.) } \\
\text { K.Schum. }\end{array}$ & 40 & 21 & 3 & 4 & cupuaçu & 1964* \\
\hline \multicolumn{7}{|l|}{ MELIACEAE } \\
\hline Azadirachta indica A. Juss. & - & - & - & 2 & nim, din & 1695 \\
\hline Carapa guianensis Aubl. & - & 1 & - & - & andiroba & 1750* \\
\hline \multicolumn{7}{|l|}{ MORACEAE } \\
\hline Artocarpus heterophyllus Lam. & 4 & - & - & 2 & jaca & 1971 \\
\hline \multicolumn{7}{|l|}{ MUSACEAE } \\
\hline Musa paradisiaca L. & 64 & 65 & 16 & 16 & banana & 1949 \\
\hline \multicolumn{7}{|l|}{ MYRTACEAE } \\
\hline Calyptranthes clusiifolia O. Berg & - & 1 & - & - & araçarana & --- \\
\hline Eucalyptus deglupta Blume & - & - & - & 2 & eucalipto & 1966 \\
\hline Syzygium cumini (L.) Skeels & 20 & 2 & - & 5 & $\begin{array}{l}\text { jambo, jambolão, jame- } \\
\text { lão }\end{array}$ & $1972 / 1973$ \\
\hline Eugenia hyemalis Cambess. & - & 2 & - & - & murta & 1727* \\
\hline Marlierea suaveolens Cambess. & - & 1 & - & - & piruí & 1743 \\
\hline Psidium guineense Sw. & 6 & 4 & - & - & araçá & 1946 \\
\hline P. guajava L. & 15 & 39 & 15 & 4 & goiaba & 1967 \\
\hline Syzygium aromaticum (L.) Merr. \& L.M. Perry & 1 & 84 & - & - & cravo & 1963 \\
\hline
\end{tabular}


TAB.1 - CONTINUAÇÃo.

\section{OLACACEAE}

Ximenia americana L.

\section{OXALIDACEAE}

Averrhoa bilimbi L.

A. carambola L.

PASSIFLORACEAE

Passiflora edulis Sims

Passiflora sp.

PEDALIACEAE

Sesamum indicum L.

PHYLLANTHACEAE

Phyllanthus niruri L.

PHYTOLACCACEAE

Petiveria alliacea L.

PIPERACEAE

Peperomia pellucida (L.) Kunth

Piper callosum Ruiz \& Pav.

P. marginatum Jacq.

P. tuberculatum Jacq

PLANTAGINACEAE

Scoparia dulcis L.

POACEAE

Cymbopogon citratus (DC.) Stapf.

Saccharum officinarum $\mathrm{L}$.

Chrysopogon zizanioides (L.) Roberty

PORTULACACEAE

Portulaca grandiflora Hook.

P. pilosa $\mathrm{L}$.

TALINACEAE

Talinum triangulare (Jacq.) Willd.

ROSACEAE

Rosa chinensis var. minima (Sims) Voss

$R$. chinensis Jacq.

RUBIACEAE

Calycophyllum spruceanum (Benth.)K. Schum.

Coffea arabica L.

Ixora coccinea L.

\section{RUTACEAE}

Citrus limon (L.) Osbeck

C. sinensis (L.) Osbeck

Citrus sp.

C. vulgaris Risso

Ruta graveolens L.

SAPOTACEAE

Manilkara zapota (L.) P. Royen

Pouteria macrophylla (Lam.)Eyma.

SIMAROUBACEAE

Quassia amara L.

\section{SIPARUNACEAE}

Siparuna guianensis Aubl.

SOLANACEAE

Capsicum annuum L. var. annuum

C. annuum var. glabrisculum (Dunal) Heiser

\& Pickersgill

C. baccatum var. umbilicatum Hunz \&

Barboza

\begin{tabular}{|c|c|c|c|c|c|}
\hline 9 & 10 & 6 & - & ameixa & 1945 \\
\hline 1 & - & - & - & limão-caiena & 1989 \\
\hline 1 & 5 & 1 & 1 & carambola & 1686 \\
\hline 1 & 8 & 2 & 1 & maracujá & 1692 \\
\hline 2 & - & - & - & maracujá-do-mato & 1754* \\
\hline 1 & - & - & - & gergelim preto & 1788 \\
\hline- & 1 & - & 1 & Quebra-pedra & 1983* \\
\hline 2 & 91 & 32 & - & mucuracá & $1736 *$ \\
\hline 1 & 1 & - & 1 & erva-de-jabuti & $1688^{*}$ \\
\hline 1 & - & - & - & elixir paregórico & $1798^{*}$ \\
\hline- & 6 & - & - & $\begin{array}{l}\text { pimenta-do-mato, mal- } \\
\text { varisco }\end{array}$ & 1849* \\
\hline- & 50 & - & - & pimenta-de-macaco & $1806 *$ \\
\hline 1 & 1 & - & - & vassourinha & 1997* \\
\hline 32 & 4 & 1 & 1 & capim-santo & 1954 \\
\hline- & 9 & - & - & cana & 1953 \\
\hline 1 & 5 & 1 & - & patchouli & 1990* \\
\hline 1 & - & - & - & onze-horas & 1936 \\
\hline 1 & - & - & 3 & amor crescido & 1687 \\
\hline 1 & - & - & - & caruru & 1779 \\
\hline 4 & 1 & - & - & rosa, roseira & 1765 \\
\hline 2 & 1 & - & - & pau-mulato & 1992* \\
\hline 2 & - & - & - & café & 1952 \\
\hline- & - & 1 & - & - & 1769 \\
\hline 18 & 5 & 3 & 3 & limão & 1678 \\
\hline 96 & 47 & 38 & 33 & Tangerina, laranja & $1995 / 1725$ \\
\hline- & 1 & 3 & - & limão tangerina & 1994 \\
\hline- & 1 & 2 & - & limão galego & 1993 \\
\hline 12 & - & - & 2 & arruda & 1679 \\
\hline 1 & 2 & - & - & sapotilha & 1996 \\
\hline 2 & 1 & - & 1 & abiu, cutite & $1791^{*}$ \\
\hline- & - & 1 & - & quiina & --- \\
\hline 1 & 2 & 1 & - & capitiú & 1729* \\
\hline- & - & 4 & - & pimenta-de-cheiro ardosa & 1821 \\
\hline 1 & - & - & - & pimenta-de-mesa & 1780 \\
\hline 1 & - & - & - & $\begin{array}{c}\text { pimenta-de-cheiro ver- } \\
\text { melha/amarela }\end{array}$ & 1834 \\
\hline
\end{tabular}


TAB.1 - CONTINUAÇÃo.

\begin{tabular}{|c|c|c|c|c|c|c|}
\hline C. chinense Jacq. & 2 & - & 4 & 1 & $\begin{array}{l}\text { pimenta-de-cheiro/ ta- } \\
\text { cacá }\end{array}$ & 1830 \\
\hline C. frutescens L. & 9 & 53 & 12 & 8 & pimenta-malagueta & 1826 \\
\hline Physalis angulata L. & 2 & 2 & - & - & camapú & 1776 \\
\hline Solanum stramoniifolium Jacq. & 1 & 20 & - & - & jurubeba & $1975^{*}$ \\
\hline \multicolumn{7}{|l|}{ URTICACEAE } \\
\hline Laportea aestuans (L.) Chew & - & 1 & - & - & urtiga & 1998* \\
\hline \multicolumn{7}{|l|}{ VERBENACEAE } \\
\hline Lippia alba (Mill.) N.E.Br. ex P. Wilson & 15 & 17 & 1 & 42 & erva-cidreira & 1680 \\
\hline Aloysia citriodora Palau & 2 & - & - & 1 & camelitana & 1676 \\
\hline Stachytarpheta cayennensis (Rich.) Vahl & 1 & - & - & 1 & erva-rinchão & $1797 *$ \\
\hline \multicolumn{7}{|l|}{ ZINGIBERACEAE } \\
\hline Curcuma longa L. & - & 1 & - & - & mangarataia & 1745 \\
\hline Renealmia guianensis Maas & - & 30 & 2 & 1 & vindicá & 1748 \\
\hline Zingiber officinale Roscoe & 32 & 1 & 25 & 2 & gengibre & 1674 \\
\hline TOTAL (155) & 1186 & 1557 & 453 & 1945 & - & - \\
\hline
\end{tabular}

Obs: $*$ = Plantas nativas do local encontradas nos quintais inventariados; --- = espécies exóticas sem representante nos herbários HAMAB e RB.

De acordo com Florentino, Araujo \& Albuquerque (2007) o hábito de cultivar plantas nativas pode ser uma alternativa para diminuir a pressão de uso da vegetação no entorno das comunidades, e também um modo de promover a sustentabilidade das espécies e conservar a diversidade local.

As diferenças na riqueza entre as áreas podem ser visualizadas nas curvas de rarefações (Fig. 2), pois ao se comparar o número de es- pécies nas quatro localidades, 30 espécies foram comuns às quatro áreas (Tab. 1), destacam-se, Curiaú de Fora que obteve a maior riqueza com 110 espécies, seguido por Curiaú de Dentro com 94. E somente a localidade de Curiaú de Fora não apresentou um comportamento assintótico, demonstrando que mais espécies poderiam ser encontradas, já que as demais localidades apresentaram sinais de estabilização das curvas, indicando que o esforço amostral foi suficiente.

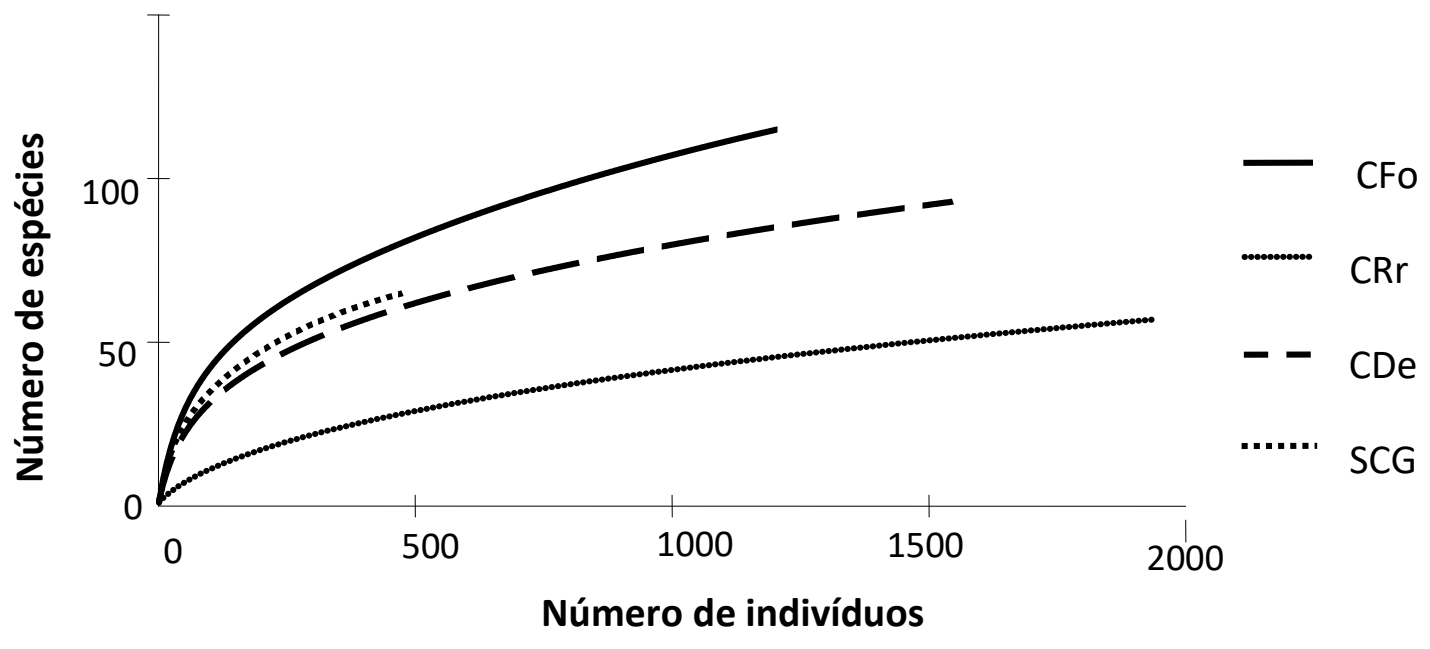

Fig. 2. Curvas de rarefação para o total de nomes populares citados na turnê-guiada realizada nas quatro localidades estudadas, de acordo com o número de entrevistas (CFo = Curiaú de Fora; CDe = Curiaú de Dentro; CRr = Curralinho e SCG $=$ S. Francisco da Casa Grande) 
Quando se comparou a riqueza a partir das localidades que deram origem ao antigo quilombo (Curiaú de Fora e Curiaú de Dentro) e as situadas na periferia da APA (Currralinho e São Francisco da Casa Grande), as duas primeiras apresentaram maior riqueza, 139 espécies e a curva de rarefação deu sinal de crescimento, enquanto as duas mais distantes do núcleo de origem do quilombo apresentaram menor riqueza, totalizando
91 espécies e a curva de rarefação apresentou-se estabilizada (Fig. 3). Esse resultado sugere uma erosão do conhecimento nas duas localidades formadas pela migração dos quilombolas pioneiros. Acredita-se, que a constituição de novas famílias (casamento), o distanciamento dos parentes e a influência de novos hábitos, devido à entrada de outros integrantes na comunidade, provavelmente, tenham influenciado nessas mudanças.

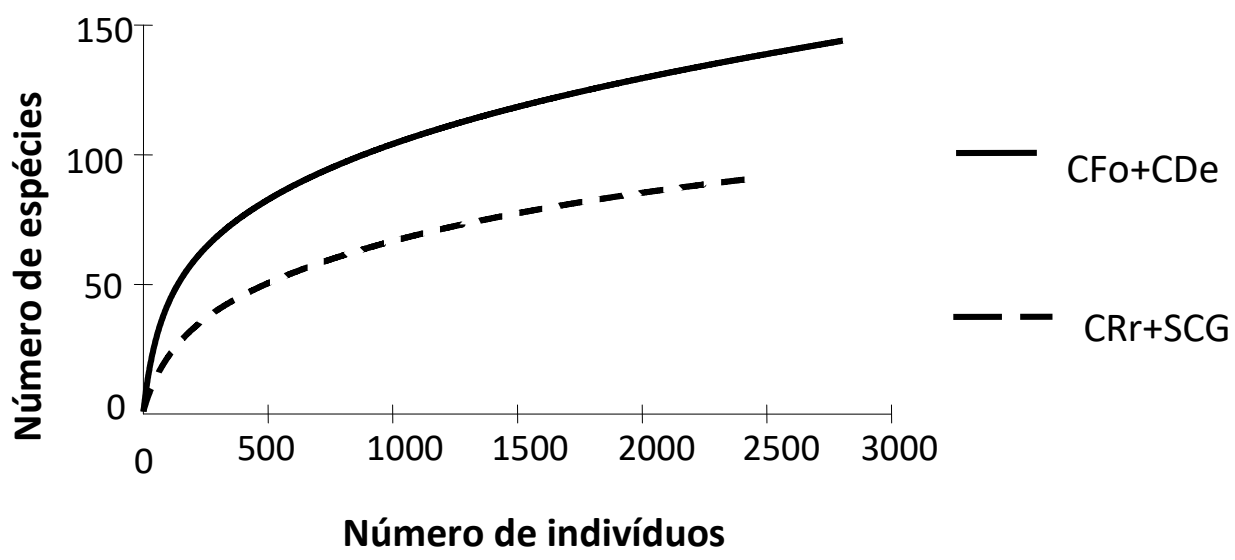

Fig. 3. Curvas rarefação para o total de plantas citadas na turnê-guiada realizada nas localidades estudadas, de acordo com o número de entrevistas, por proximidade de localidades (CFo = Curiaú de Fora $+\mathrm{CDe}=$ Curiaú de Dentro e CRr $=$ Curralinho + SCG $=$ S. Francisco da Casa Grande)

O índice de Shannon-Wiener para as localidades indicou que Curiaú de Fora, apresentou a maior diversidade $\left(H^{\prime}=3,82\right)$, seguido de Curiaú de Dentro com $\mathrm{H}^{\prime}=3,15$ (Tab. 2). Os valores do índice de Simpson e de Pielou também acompanharam tais resultados (Tab. 2). Esses dados comprovam a tese de que um local com alta riqueza vegetal não necessariamente terá uma ele- vada diversidade, uma vez que Curiaú de Fora e Curiaú de Dentro, apesar de apresentarem maior riqueza (110 e 94 espécies, respectivamente), apresentaram uma distribuição de abundâncias entre espécies menos equitativas que as ocorrentes em São Francisco da Casa Grande (1945 indivíduos/táxons) (Tab. 2).

Tab. 2. Lista das localidades estudadas na APA do Rio Curiaú com número total de quintais, número total de espécies, de nomes populares e de espécies de pimentas cultivadas. $\mathrm{H}^{\prime}$ = índice de diversidade, 1/D = índice de diversidade de Simpson e J' = índice de Pielou

\begin{tabular}{|c|c|c|c|c|c|c|c|}
\hline LOCALIDADES & $\begin{array}{c}N^{\circ} \text { DE } \\
\text { QUINTAIS }\end{array}$ & $\begin{array}{c}N^{\circ} \text { DE } \\
\text { ESPÉCIES }\end{array}$ & $\begin{array}{l}\text { No DE INDIVÍ- } \\
\text { DUOS (TAXAS) }\end{array}$ & $\begin{array}{l}N^{\circ} \text { DE ES- } \\
\text { PÉCIES DE } \\
\text { PIMENTAS }\end{array}$ & $\mathbf{H}^{\prime}$ & 1/D & $\mathbf{J}^{\prime}$ \\
\hline Curiaú de Fora & 4 & 110 & 1186 & 4 & 3,82 & 0,97 & 0,81 \\
\hline Curiaú de Dentro & 5 & 94 & 1557 & 3 & 3,15 & 0,89 & 0,69 \\
\hline $\begin{array}{l}\text { São Francisco da Casa } \\
\text { Grande }\end{array}$ & 4 & 64 & 453 & 3 & 2,10 & 0,96 & 0,50 \\
\hline Curralinho & 3 & 58 & 1945 & 2 & 0,93 & 0,29 & 0,22 \\
\hline
\end{tabular}


Miranda \& Hanazaki (2008), ao analisarem a diversidade em quintais de comunidades caiçaras no estado de Santa Catarina, encontraram diferenças entre os índices de diversidade das comunidades isoladas em relação àquelas próximas a centros urbanos; atribuem essa diferença a fatores como distância entre essas comunidades e as áreas urbanas, tempo de formação de sua população, e auto identificação como um grupo cultural distinto e coeso. Na APA do Rio Curiaú, os fatores supramencionados podem também ter exercido influência na diversidade local.

Devido à distância significativa entre as localidades estudadas e, por se tratar de uma área com remanescentes quilombolas, as características socioambientais da população local são preservadas, o que garante as tradições alimentares, medicinais e ritualísticas. Outro fator que pode ter atuado na alta diversidade de espécies foi o contínuo intercâmbio de material genético que associa a diversidade contida nos ecossistemas naturais à tradição local (Clement et al., 2001). Segundo WinklerPrins (2002) na Amazônia, os quintais são de grande importância tanto na vida rural quanto na urbana, uma vez que expressam esse "contínuo rural-urbano".

$O$ índice de equitabilidade $\left(\mathrm{J}^{\prime}\right)$ demonstrou mais uniformidade nas proporções indivíduos/espécies para a localidade de Curiaú de Fora $\left(\mathrm{J}^{\prime}=\right.$ 0,81 ) e menor para a localidade de Curralinho $\left(J^{\prime}=0,22\right),($ Tab. 2$)$. O resultado encontrado para
Curralinho (1631 indivíduos de mandioca - Manihot esculenta L.), deve-se a alta proporção de indivíduos desta espécie, presentes na área inventariada (Tab. 1), uma das espécies mais cultivadas na região, considerada base da alimentação local, da qual se produz farinha de mandioca, tapioca, tucupi, dentre outros produtos.

\section{RIQUEZA E ETNOBOTÂNICA DAS ESPÉ- CIES DE PIMENTAS}

No que se refere à riqueza de pimentas foram encontrados 151 indivíduos distribuídos em nove táxons citados pelos especialistas, em 21 nomes populares pertencentes às famílias Piperaceae e Solanaceae (Tab. 1). A maior freqüência nos quintais inventariados foi assinalada para Capsicum frutescens L. (pimenta malagueta) com 82 indivíduos.

A pimenta malagueta (C. frutescens) foi o táxon com a maior frequência nas quatro localidades inventariadas, ocorrendo em $58 \%$ dos quintais dos especialistas (Tab. 3). As pimentas com maior ocorrência foram: pimenta malagueta, pimenta malaguetinha e pimenta malaguetão ( $C$. frutescens), encontradas em 14 dos 16 quintais estudados, com elevado grau de ocorrência, em relação à segunda mais utilizada a pimenta de cheiro (Capsicum chinense Jacq.), (Tab. 3).

Tab. 3. Lista de pimentas citadas e cultivadas pelos especialistas na APA do Rio Curiaú, com respectivos Valores de Usos: VU Cit. = Valor de Uso das pimentas citadas pelos especialistas; VU Inv. = Valor de Uso das espécies inventariadas nos quintais; Frequência relativa das espécies inventariadas em percentagem (\%) nas localidades: $\mathrm{CFo}=$ Curiaú de Fora, $\mathrm{CDe}=$ Curiaú de Dentro, $\mathrm{SFC}=$ São Francisco da Casa Grande e Crr $=$ Curralinho

\begin{tabular}{|c|c|c|c|c|c|c|c|c|c|}
\hline \multirow[t]{2}{*}{ Nome CIENTÍfico } & \multirow[t]{2}{*}{ NOME POPULAR } & \multirow[t]{2}{*}{$\begin{array}{l}\text { VU } \\
\text { CIT. }\end{array}$} & \multirow[t]{2}{*}{$\begin{array}{l}\text { VU } \\
\text { INV }\end{array}$} & \multicolumn{6}{|c|}{$\begin{array}{l}\text { FREQÜÊNCIA RELATIVA DAS } \\
\text { ESPÉCIES INVENTARIADAS ( } \%)\end{array}$} \\
\hline & & & & CFo & $\mathrm{CDE}$ & SFC & $\mathrm{CRR}_{\mathrm{R}}$ & $\mathrm{T}$ & $\%$ \\
\hline $\begin{array}{l}\text { Piper marginatum } \\
\text { Jacq. }\end{array}$ & pimenta-do-mato & 0,06 & 0,13 & --- & 50 & --- & --- & 50 & 8 \\
\hline Piper tuberculatum & & 0,06 & & & & & & & \\
\hline Jacq. & pimenta-de-macaco & & 0,06 & --- & 25 & --- & --- & 25 & 4 \\
\hline Piper nigrum L. & pimenta-do-reino* & 0,13 & --- & --- & --- & --- & --- & --- & 0 \\
\hline Capsicum annuum L. & pimentão & 0,3 & --- & --- & --- & --- & --- & --- & 0 \\
\hline $\begin{array}{l}\text { C. annuum L. var. } \\
\text { annuum }\end{array}$ & pimenta-de-cheiro ardosa & 0,19 & --- & --- & --- & --- & --- & --- & 0 \\
\hline C. chinense Jacq. & pimenta-amarela ardosa & 0,06 & 0,19 & --- & --- & --- & 25 & 25 & 4 \\
\hline " & pimenta-amarela-de-cheiro & 0,19 & --- & --- & --- & --- & --- & --- & 0 \\
\hline$"$ & pimenta-camapú & 0,06 & --- & --- & --- & --- & --- & --- & 0 \\
\hline$"$ & pimenta-de-cheiro, de tacacá & 0,31 & 0,31 & 25 & --- & 25 & 25 & 75 & 13 \\
\hline$"$ & $\begin{array}{l}\text { pimenta-de-cheiro de panela } \\
\text { pimenta-de-cheiro redondi- }\end{array}$ & 0,68 & 0,06 & --- & --- & --- & 25 & 25 & 4 \\
\hline$"$ & nha ardosa & 0,06 & --- & --- & --- & --- & --- & --- & 0 \\
\hline
\end{tabular}


TAB. 3 . CONTINUAÇÃo.

\begin{tabular}{|c|c|c|c|c|c|c|c|c|c|}
\hline \multicolumn{10}{|l|}{$\begin{array}{l}\text { C. annuum var. gla- } \\
\text { brisculum (Dunal) }\end{array}$} \\
\hline Heiser \& Pickersgill & pimenta-de-mesa & 0,13 & 0,13 & 25 & --- & --- & --- & 25 & 4 \\
\hline " & pimenta-açaí & 0,06 & --- & --- & --- & --- & --- & --- & 0 \\
\hline$"$ & pimenta-peito-de-moça & 0,19 & --- & --- & --- & --- & --- & --- & 0 \\
\hline$"$ & pimenta-ova-de-aruanã & 0,36 & --- & --- & --- & --- & --- & --- & 0 \\
\hline$"$ & pimenta-ova-de-tamuatá** & 0,06 & --- & --- & --- & --- & --- & --- & 0 \\
\hline$"$ & pimenta-chumbinho & 0,06 & --- & --- & --- & --- & --- & --- & 0 \\
\hline $\begin{array}{l}\text { C. baccatum var. } \\
\text { umbilicatum (Vell.) }\end{array}$ & & & & & & & & & \\
\hline Hunth et Barboza & pimenta-de-cheiro amarela & 0,06 & 0,06 & 25 & --- & --- & --- & 25 & 4 \\
\hline C. frutescens $\mathrm{L}$. & pimenta-malagueta & 2,56 & 3,00 & 100 & 100 & 75 & 75 & 350 & 58 \\
\hline & pimenta-malaguetão* & 0,25 & --- & --- & --- & --- & --- & --- & 0 \\
\hline$"$ & pimenta-malaguetinha* & 0,25 & --- & --- & --- & --- & --- & --- & 0 \\
\hline Média & & 0,55 & 0,25 & 175 & 175 & 100 & 150 & 600 & 100 \\
\hline
\end{tabular}

Nos dois quintais onde não foram encontradas pimentas, foi indagado o porquê da ausência das mesmas. Um dos especialistas justificou que tinha desistido do plantio devido à falta de local adequado e por causa da existência de animais soltos (gado, porco, galinha, dentre outros) que comiam todas as pimenteiras; porém, acrescentou que tinha sementes de pimenta malagueta guardadas em sua casa. O outro justificou que devido a sua idade (80 anos), não dispunha de força física suficiente para plantar.

As espécies de pimentas cultivadas pelos especialistas são táxons que ocorrem em várias regiões do Brasil (Buso et al., 2003; Csilléry, 2006; Guimarães \& Giordano, 2004), principalmente na Amazônia brasileira (Andrade et al., 2008), com exceção de Piper nigrum L. (pimenta-do-reino), muito usada na culinária local, porém não assinalada nos inventários, embora tenha sido observado o seu cultivo em quintais não inventariados na região do Curiaú. Os táxons Piper marginatum Jacq e Piper tuberculatum Jacq, também denominados "pimentas", são espécies nativas do local, com ocorrência espontânea no entorno dos quintais e, não raro, cultivados nas residências dos quilombolas, geralmente usados como medicinais e/ou ritualísticos. Segundo Guimarães \& Giordano (2004) muitas pimentas, principalmente as pertencentes ao gênero Piper L. (Piperaceae) são utilizadas em outros locais da Amazônia, Nordeste e Sudeste brasileiro para os mesmos fins, a exemplo de Piper hispidinervum DC., Piper callosum Ruiz \& Pav., dentre outras.

\section{Uso e Cultivo de PIMENTAS}

Em relação às 88 citações de usos (Fig. 4), mencionadas pelos especialistas, $65 \%$ foram definidas como alimento, $15 \%$ como medicinal e $14 \%$ como ritualística.

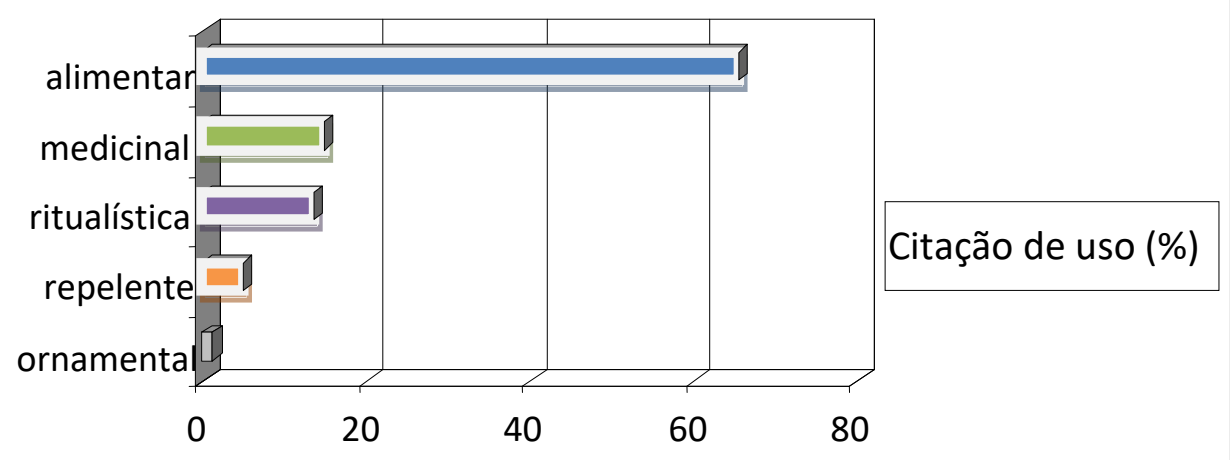

Fig. 4. Percentual de categorias de usos das pimentas citadas pelos especialistas da APA do Rio Curiaú 
Quando foi analisado o valor de uso a partir das citações efetuadas nas entrevistas, a pimenta malagueta novamente apareceu como a planta com maior valor de uso ( $\mathrm{VU}=2,56)$, comprovando assim, a versatilidade de uso dessa pimenta dentre os especialistas estudados (Tab. 3), que consideram C. chinense e $C$. frutescens como plantas com poder de afastar "mau-olhado", curar "panemeira" e "dá boa sorte em tudo", o que corrobora os dados de Pereira et al. (2007) para a mesma região. Maués \& Villacorta (2001) informam que a "panemeira", geralmente provocada pela feitiçaria, é classificada como um estado ou condição que leva ao insucesso nas atividades produtivas ou que não consegue obter o êxito contínuo desejado, sendo possível ser tratada com banhos usando substâncias fétidas, ardidas ou prurientes.

Neste estudo foi possível notar que o plantio de pimenteiras nos quintais estudados é muito influenciado pelo misticismo, principalmente a pimenta malagueta que é bastante cultivada em frente às residências e, segundo os especialistas, os "antigos" (antepassados) diziam que essa planta tinha um poder sobrenatural de afastar pessoas com "mau olhado" e/ou "olho gordo" (termo usado para expressar inveja). Além disso, esta planta possui inúmeras indicações fitoterápicas, a exemplo, o emprego da folha, que de acordo com uma das entrevistadas, têm poderes tanto medicinais quanto sobrenaturais.

"A folha é bom para "ensipela" (erisipela), espinha no rosto... murcha a folha da pimenta coloca um pouquinho de "sebo de holanda" e coloca em cima... o sumo dela é bom também pra brotoeja... tira o sumo e coloca uma pitadinha de sal e passa no local... é bom pra benzer também: quebra o galho e benze, a planta vai ficar murcha por causa da doença... a pimenta malagueta para defumação é muito boa, pega a folha da pimenta e bota numa vasilha com brasa e defuma a arma do caçador... serve pra tirar a "panemeira". (Especialista da comunidade Curiaú de Fora).

De um modo geral essas espécies são utilizadas para fins ritualísticos, não raro, em forma de banho, segundo a indicação efetuada pelos especialistas da APA; para eles o "mau-olhado (e.g "quebranto") diz respeito a um tipo de doença classificada como "doenças da alma". Amorozo (2002) estudando os usos terapêuticos de plantas no município de Santo Antônio do Laverger (MT) classifica estas práticas não apenas como de cunho ritualístico, mas do universo nosológico das comunidades estudadas.

Consulta a uma taxonomista em Solanaceae, revelou que do ponto de vista taxonômico, as três plantas citadas pelos especialistas locais com nomes populares diferentes, correspondem à mesma espécie, C. frutescens. Entretanto, estas apresentam características genotípicas iguais, sendo seus fenótipos distintos pela coloração, tamanho das folhas, pétalas e frutos. As pimentas malaguetinha e malaguetão são diferenciadas pelo tamanho do fruto - a primeira com cerca de $1,5 \mathrm{~cm}$ de comprimento e a segunda com 4,5$5,0 \mathrm{~cm}$ de comprimento, e pelas pétalas, verde claro, para a malaguetinha e verde escuro para a malaguetão. Entrentanto, a análise efetuada nos órgãos reprodutivos dos três tipos de pimentas, não revelaram diferenças morfológicas significativas, consequentemente, são tratadas aqui como um mesmo táxon.

As pesquisas demonstraram que os especialistas não reconhecem as três pimentas como idênticas, entretanto, as utilizam para as mesmas finalidades (medicinal e ritualística), provavelmente, devido às várias semelhanças morfológicas que esses táxons possuem. Apesar de ter sido observada a presença da pimenta malagueta (C. frutescens) na maioria dos quintais inventariados, apenas um dos especialistas do sexo masculino, admitiu saber usar as folhas das pimenteiras sob a forma de chás e emplastos. Isto revela que essa prática de usar plantas como remédios é mais comum entre as mulheres. E provavelmente está relacionado com a troca de informações cotidianas entre as mães e as filhas, do que entre elas, os filhos (meninos) e os maridos.

Dos oito especialistas do sexo masculino entrevistados, apenas dois afirmaram com segurança que acreditavam nas propriedades fitoterápicas das pimenteiras, porém, um deles deixou transparecer incerteza na eficácia quanto ao tratamento ou cura, em casos de doenças e, nenhum afirmou ter conhecimento sobre o uso das raízes como medicinal. Além disso, todos frisaram que na cultura local é a mulher quem domina a forma de uso das pimentas. Em geral, nas conversas com tais especialistas, os mesmos relataram que utilizam as pimentas apenas como alimento, não demonstrando preocupação sobre questões econômicas, ritualísticas e medicinais, assuntos considerados também de âmbito feminino. A única exceção, foi apenas de um deles quando mencionou o misticismo local, admitiu acreditar que existam poderes sobrenaturais das pimenteiras contra "olho-gordo" e "mau-olhado". Para ele, algumas pessoas podem ser "carregadas", ou seja, apresentam a capacidade de secar ou matar uma planta através de um simples olhar. Essa crença, comum entre os moradores das localidades estudadas, também foi detectada por Azevedo \& Silva (2006), Bernardes \& Ferreira (2007) em estudos realizados com populações tradicionais brasileiras em outras regiões do Brasil.

Em relação ao desenvolvimento do cultivo local, os quilombolas plantam as pimentas consideradas por eles mais raras (e. g C. annuum L. e C. baccatum var. umbilicatum Hunz. \& Barboza) em "girais" suspensos, de modo a protegê-las do consumo dos animais. Estas pimentas inicialmente são plantadas em recipientes com terra preta e 
quando alcançam cerca de 10 a $15 \mathrm{~cm}$ de altura, são transportadas para o plantio definitivo, usando esterco de gado ou de galinha como adubo, um cultivo que exige bastante água para o seu desenvolvimento, principalmente nos devido de agosto a dezembro, período de baixo índice de precipitação pluviométrica.

Assinala-se ainda, que neste local é muito comum a ação de formigas e lagartas, geralmente controladas pelo uso de inseticidas. Entretanto, foi observado em alguns locais da APA, o uso do controle biológico de insetos, conforme método descrito por Gravena (1992) feito no local, geralmente com a ajuda do Instituto de Desenvolvimento Rural do Amapá (RURAP), órgão responsável pelo serviço de Extensão Rural no Estado.

A pimenta malagueta não tem ocorrência nativa no local, porém é espontânea na APA, fato observado por Yamamoto \& Nawata (2009) nas ilhas de Taiwan (Ásia Oriental) e Batanes (Norte das Filipinas). A ocorrência de plantas que nascem espontaneamente nos quintais ou nas roças é popularmente chamada pelos moradores "de plantas que grelam", devido a dispersão de sementes por pássaros e/ou outros animais. Outro fator que contribui para a ocorrência dessas plantas nos quintais é a semeadura aleatória das sementes efetuadas pelas mulheres em seus quintais, principalmente das sementes de pimenta malagueta, cultivo elaborado com o intuito de evitar a perda das variedades cultivadas.

Para os especialistas consultados, a presença da pimenta malagueta em suas roças é positiva, pois ajuda a amenizar as perdas com o cultivo do arroz, milho, dentre outros, uma vez que contribui para o aumento do estoque de alimentos principalmente para os pássaros, um dos principais predadores em suas roças, garantindo assim, maior lucro na produção.

O plantio de pimentas nas residências é uma atividade praticada pelas mulheres e filhos, embora dentre os consultados do sexo masculino, apenas dois declararam que plantavam pimenteiras em seus quintais.

Os especialistas de uma maneira geral não se mostraram motivados a introdução de novas pimentas em seus quintais, devido a um acordo no que se refere à restrição do uso de cercas nas propriedades dentro da APA. Assim, segundo eles, falta um local apropriado para o plantio de novas pimentas nos quintais. Acrescentaram ainda, que grande parte dos moradores cria animais domésticos como galinhas, porcos, gados, que juntamente com os pássaros nativos contribuem para o desaparecimento dos cultivos e, conseqüentemente, as pimenteiras plantadas não conseguem atingir o estágio de floração e/ou frutificação. Esse fato pode ser um dos indicativos para a perda das pimentas citadas nas entrevistas e que não foram encontradas nos quintais inventariados. Isso pode ser observado nas pimentas que obtiveram baixo $\mathrm{VU}$, a exemplo das pimentas açaí, ova de aruanã e ova de tamuatá [Capsi- cum annuum var. glabrisculum (Dunal) Heiser \& Pickersgill], dentre outras, com VU =0,06 (Tab. $3)$. Essa perda da diversidade pode estar relacionada ao modo de vida da população estudada, onde se observou que, para eles o crescimento espontâneo da pimenta malagueta é suficiente para suprir as suas necessidades.

Existe um elo muito importante entre a necessidade de proteção e a cura das enfermidades pelo uso da pimenta malagueta. Essa necessidade pode decorrer dos processos relacionados às práticas ritualísticas, alimentares e medicinais, atribuídas a essa pimenta. Segundo os especialistas da região estudada, há uma crença difusa no que se refere ao hábito de comer a pimenta malagueta; para eles, esta é a única que pode ser ingerida sem o risco de causar algum tipo de desconforto estomacal, mesmo nas pessoas que por ventura sofram de algum tipo de enfermidades gastrointestinais e/ou problemas de hemorróidas.

\section{IMPORTÂNCIA SOCIOECONÔMICA DAS PIMENTAS}

Para os especialistas as pimentas são pouco comercializadas, no entanto, são profusamente consumidas no uso doméstico, como recursos alimentícios, medicinais, ritualísticos e repelentes (Fig. 4). Ficou evidente o desinteresse dos mesmos em relação à utilização das pimentas como produto para a venda, pois apesar das mesmas terem uma ocorrência alta nos quintais estudados, essas não vem sendo cultivadas para tal fim. Apesar da grande quantidade de espécies vegetais úteis encontradas nos quintais estudados, poucas pimentas foram observadas no inventário, o que pode indicar uma rápida descaracterização da cultura local, uma vez que $37 \%$ dos especialistas demonstraram ter preferência em comprar pimentas nas feiras ou supermercados, a cultivá-las em seus domicílios como era realizado no passado. Neste estudo foi observado, por exemplo, que a pimenta de cheiro tacacá, pimenta de cheiro de panela (C. chinense), dentre outras, tiveram um declínio no contexto socioeconômico e cultural da população local.

No que tange à comercialização de produtos agrícolas, incluindo as pimentas, verificou-se que a venda é realizada em frente às residências e no comércio local. É importante mencionar que apesar de algumas pimentas serem bastante cultivadas nos quintais seus produtos vêm sendo pouco aproveitados como alternativa de renda para os quilombolas da APA do Rio Curiaú.

\section{CONSIDERAÇÕES FINAIS}

A diversidade de espécies úteis é bastante representativa e os dados confirmam a elevada riqueza encontrada na maioria dos quintais amazônicos. 
A categoria de uso que mais agregou espécies foi a medicinal, seguido de alimentar, embora não se possa afirmar que os especialistas dependam apenas dessas plantas para curar suas doenças, destaca-se que as mesmas são importantes no cotidiano local.

Foi possível notar que o conhecimento sobre o uso e cultivo de pimentas está restrito nas residências às mulheres (Mães e filhas), tendo-se percebido que os filhos (homens) pouco participam do processo de transmissão desse conhecimento.

Um dos fatores da rápida descaracterização cultural que a comunidade vem sofrendo, pode estar sendo causado pelo desinteresse dos quilombolas em continuar utilizando pimentas como recursos medicinais, pois é clara a preferência em adquirir remédios alopáticos do que utilizar o saber dos seus ancestrais, caracterizando assim, uma notável erosão no conhecimento local.

É marcante o plantio da pimenta malagueta em grande parte das residências visitadas na APA, devido a sua versatilidade de uso, porém notou-se que o plantio está concentrado principalmente nas mãos das mulheres, apesar de se notar que atualmente a sua ocorrência esteja acontecendo mais de forma espontânea na floresta, devido à dispersão pelos pássaros. Assinala-se também a importância das mulheres admitirem que armazenam sementes para semear nos períodos mais apropriados, manejando-as de tal forma que se evitem perdas, mantendo vivo o saber local.

Notou-se também que os especialistas cultivam uma quantidade significativa de plantas nativas em seus quintais, além de apresentarem profundo conhecimento sobre o uso das cultivadas, consequentemente este saber pode ser utilizado como uma das estratégias alternativas para elaboração de um plano de manejo visando à conservação da diversidade local.

Sugere-se que o poder público juntamente com a comunidade quilombola inclua as pimentas além de outras plantas, como um dos produtos com potencial de geração de renda sustentável, procurando utilizar as espécies citadas, com o intuito de melhorar a qualidade de vida local e garanta a conservação in situ das variedades locais.

Por fim, sugere-se ainda, que o Órgão de extensão rural do Estado (RURAP), juntamente com a Universidade do Estado do Amapá (UEAP), desenvolvam projetos sobre o uso de pimentas procurando incluir os jovens (ambos os sexos), de forma a repassar os conhecimentos dos seus ancentrais visando as futuras gerações.

\section{Agradecimentos}

Os autores agradecem aos moradores da APA do Rio Curiaú pelas informações prestadas, à Gloria Estela Barboza da Universidade Nacional de
Córdoba (Argentina) pelas informações sobre as espécies e identificações dos exemplares da família Solanaceae, à Claudia Funi pela elaboração do mapa, a Thalita dos Santos Mendes pela atualização dos nomes científicos e à Denise Pinheiro da Costa, Nivea Dias dos Santos, Isaí Jorge de Castro pelas contribuições e críticas ao texto.

\section{REFERÊNCIAS}

Albuquerque, U.P. 2005. Etnobiologia e biodiversidade. In: Hanazaki, N. (Org.) Série "Estudos e debates". Recife: Editora Livro Rápido, NUPEEA/Sociedade Brasileira de Etnobiologia e Etnoecologia, p. 14-58.

Albuquerque, U.P. \& R.F.P. Lucena. 2008. Métodos e técnicas para coleta de dados. In: Albuquerque, U.P. (Org.) Métodos e técnicas na pesquisa etnobotânica. Recife, Editora NUPEEA, p. 37-55.

AMAPA (Estado). LEI 0431 dispõe sobre a criação da Área de Proteção Ambiental do Rio Curiaú. Diário Oficial do Estado. Amapá, 15 de set. 1998. Disponivel em: <http://www.al.ap.gov.br/ver_texto_lei. php?iddocumento $=877>$. Acesso em: 15 out. 2016.

Amorozo, M.C.M. 2002. Uso e diversidade de plantas medicinais em Santo Antonio do Leverger, MT, Brasil. Acta Botânica Brasílica. 16(2): 189-203.

Andrade, E.H., L.M. Carreira, M.H.L da Silva, J. Domingos da Silva, C. Bastos, P.J. Souza, E.F. Guimarães \& J.G.S. Maia. 2008. Variability in essential essential-oil composition of Piper marginatum sensu lato. Chemic Biodiversity. 5, p. 197-208.

APG IV (Angiosperm Phylogeny Group III). 2016. An update of the Angiosperm Phylogeny Group classification for the orders and families of flowering plants: APG IV. Botanical Journal of the Linnean Society 181: $1-20$.

Azevedo, S.K.S. \& I.M. Silva. 2006. Plantas medicinais e de uso religioso comercializadas em mercados e feiras livres no Rio de Janeiro, RJ, Brasil. Acta Botânica Brasílica. 20(1): 185-194.

Bailey, K. D. 1982. Methods of social research. New York: The Free Press. 
Bernardes, O.S. \& D.T. Ferreira. 2007. Química de plantas psicotrópicas místicas. Rev. Eletrônica da UEL. Disponível em: <http://www2.uel. br/revistas/afroatitudeanas/volume-2-2007/ Priscilla.pdf $>$. Acesso em: 27 nov. 2008.

Brito, D.M.C. \& J. Drummond. 2007. O planejamento e o zoneamento participativos: novos instrumentos de gestão para as unidades de conservação do Brasil (O caso da Área de Proteção Ambiental do Rio Curiaú Amapá). RGSA. V. 1, n. 3. p. 12-131. Disponível em : <http://www.ufpa.br/numa/PPGEDAM/ edital\%202009?Brito_Daguinete_Chaves. pdf>. Acesso em: 28 ago. 2009.

Buso, G.C.S., Z.P.S. Amaral, L.B. Bianchetti, F.R.B. Machado \& M.E. Ferreira. 2003. Genetic variability and philogenetic analysis of brazilian species of Capsicum. Capsicum \& Eggplant Newsletter, V. 22, p. 13-16.

Clement, C.R., H. Noda, S.N. Noda, A.L.U. Martins \& G.C. Silva. 2001. Recursos frutícolas na várzea e na terra firme em onze comunidades rurais do Alto Solimões, Amazonas, Brasil. Acta Amazonica, 31(3): 521527.

Colwell, R.K. 2005. Estimates: Statistical estimation of species richness and shared species form samples. Versão 7.5. Disponível em: <http://purl.oclc.org/estimates>. Acesso em: 10 fev. 2011.

Csilléry, G. 2006. Taxonomy and the botanical description of the species Pepper. Acta Agron. Hungarica. 54(2): 151-166.

Empresa Brasileira de Pesquisas Agropecuárias (EMBRAPA). Disponível em: <http:// www.cpaa.embrapa.br/portfolio/sistemadeproducao/prosiaf/SISAFpagina/WebSisaf/ SISAF1.php>. Acesso em: 07 mar. 2007.

Fernandes, E.C.M. \& P.K.R. Nair. 1986. An evaluation of the structure and function of tropical homegardens, Agoforestry Systems 21: 279-310.

Fidalgo, O. \& V.L.R. Bononi. 1984. Técnicas de coleta, apresentação e herborização de material botânico. São Paulo: Instituto de Botânica, 62 p. (Manual, n. 4).

Figueiredo, G.M., H.F. Leitao Filho \& A. Begossi.1993. Ethnobotany of Atlantic Forest coastal communities: diversity of plant uses in Gamboa (Itacuruca Island, Brazil). Human Ecology 21: 419-430.
Florentino, A.T.N., E.L. Araujo \& U.P. Albuquerque. 2007. Contribuição de quintais florestais na conservação de plantas da Caatinga, Município de Caruaru, PE, Brasil. Acta Botânica Brasílica. 21(1): 37-47.

Fonseca-Kruel, V.S. \& A.L. Peixoto. 2004. Etnobotânica na reserva extrativista marinha de Arraial do Cabo, RJ, Brasil. Acta Botânica Brasílica. 18: 77-190.

Flora do Brasil 2020 em construção. Jardim Botânico do Rio de Janeiro. Disponível em: < http://floradobrasil.jbrj.gov.br/ >. Acesso em: 22 Nov. 2016

Gravena, S. 1992. Controle biológico no manejo integrado de pragas. Brasilia. Pesq. Agropec. Bras., 27:281-299.

Guimarães, E.F. \& L.C.S. Giordano. 2004. Piperaceae do nordeste brasileiro I: estado do Ceará. Rio de Janeiro, Rodriguésia. v. 55, n. 84, p. 21-46.

McAleece, N., P. J. D. Lambshead \& G. L. J. Paterson. 1997. BioDiversity Pro (version 2). Londres, the Natural History Museum e the Scottish Association for Marine Science. Disponivel em: <http://gcmd.nasa.gov/records/NHML_Biopro.html>. Acesso em: 20 fev. 2011.

Hammer, O., D. A. T. Harper \& P. H. Ryan. Past Palaeontological Statistics, ver. 2.07. Disponivel em: < http://folk.uio.no/ohammer/past/>. Acesso em: 23 fev. 2011.

Hanazaki, N., J.Y. Tamashiro, H.F. Leitao FiIho \& A. Begossi. 2000. Diversity of plants uses in two Caicara communities from the Atlantic Forest coast, Brazil. Biodiversity and Conservation 9: 597-615.

Instituto Brasileiro de Geografia e Estatística (IBGE). Mapa dos biomas do Brasil: primeira aproximação. 2004. Disponível em: <http://www.ibge.gov.br>. Acesso em: 02 mar. 2011.

Leão, R.B.A., M.R.C. Fereira \& M.A.G. Jardim. 2007. Levantamento de plantas de uso terapêutico no município de Santa Bárbara do Pará, Estado do Pará, Brasil. Revista Brasileira de Farmácia, 88(1): 21-25.

Magurran, A.E. 2004. Measuring Biological Diversity. Blackwell Publishing, Malden, USA, $256 p$. 
Maués, R.H. \& G.M. Villacorta. 2001. Pajelança e encantaria amazônica. In: Prandi, R. (Org.) Encantaria Brasileira: O livro dos mestres, caboclos e encantados. Rio de Janeiro: Pallas. v., p. 11-58.

Ming, L.C. \& A. Amaral Junior. 2003. Ethobotanical aspects of medicinal plants in the Chico Mendes Extractive Reserve. In: Daly, D., Silveira, M. (Org.) Floristics and Economic Botany of Acre, Brazil. $1^{a}$ ed. Nova York: The New York Botanical Garden/Univ. Federal do Acre, v. 1, p. 1-38.

Miranda, T.M. \& N. Hanazaki. 2008. Conhecimento e uso de recursos vegetais de restinga por comunidades das ilhas do Cardoso (SP) e de Santa Catarina (SC), Brasil. Acta Botânica Brasilica. 22(1): 203-215.

МОвот. 2016. Missouri Botanical Garden, W3 Tropicos. Specimen Data Base. Disponível em: http://www.mobot.org/plantscience/ W3T/Search/vas.html. Acesso em: 09 nov. 2016.

Nair, P.K.P. 1986. An Evaluation of the Struture and Function of Tropical Homegardens. Agricultural Systems. 21: 279-310.

Pereira, L.A., R.B.L. Silva, E.F. Guimarães, M.Z. Almeida, E.D.C.Q. Monteiro \& F.A.P. Sobrinho. 2007. Plantas medicinais de uma comunidade quilombola na Amazônia Oriental: Aspectos utilitários de espécies das famílias Piperaceae e Solanaceae. Revista Brasileira de Agroecologia. V. 2. 385 p. Disponivel em: <http://www6. ufrgs.br/seeragroecologia/ojs/viewarticle. php?id=1498\&locale=en. $>$. Acesso em: 15 fev. 2010.

Phillips, G. \& A.H. Gentry. 1993. The useful plants of Tambopata, Peru: I. Statistical hypotheses tets with a new quantitative technique. Economic Botany. 47(1): 15-32.

Rossato, S.C., H. Leitão-Filho \& A. Begossi. 1999. A Ethnobotany of Caiçaras of the Atlantic Forest Coast (Brazil) Economic Botany, 53(4):387-395.

Rotta, E., L.C. Carvalho \&, M.Z. Beltrami. 2008. Manual de prática de coleta e herborização de material botânico [recurso eletrônico] - Dados eletrônicos. - Colombo: Embrapa Florestas, 2008.1 CD-ROM. - (Documentos/ Embrapa Florestas, ISSN 16792599; 173.
Secretaria de Estado do Meio Ambiente. Coordenadoria de Gestão de Unidade de Conservação. 2010. Plano de manejo da APA do Rio Curiaú. Macapá, 220p.

Silva, R.B.L. 2002. A etnobotânica de plantas medicinais da comunidade quilombola de Curiaú, Macapá-AP, Brasil. Dissertação Mestrado em Agronomia-Universidade Federal Rural da Amazônia, Belém. Disponivel em: <www. iepa.ap.gov.br/arquivopdf/etnobotanica_ de_plantasmedicinaisdo_Curiau.pdf $>$. Acesso em: 23 dez. 2010.

Silva F.A. \& L. Rebellato. 2004. Use of space and formation of Terra preta: The asurini do Xingu case estudy. In Glaser, B., Woods, W.I. (Ed.). Exploration in Amazonian Dark Earths. Springer. p. 159-167.

Silva, J. M. C., A. Rylands \& G. A. B. da Fonseca. 2005. O destino das áreas de endemismo da Amazônia. Megadiversidade, v. 1, n. 1 , p. 124-131.

Souza, V. C. \& H. Lorenzi. 2008. Botânica Sistemática: guia ilustrado para identificação das famílias de Fanerógamas nativas e exóticas no Brasil, baseado em APG III, 3a. ed. Instituto Plantarum: Nova Odessa.

Thiers, B. Index Herbariorum: a global directory of public herbaria and associated staff. Disponível em: <http://sweetgum.nybg.org/ ih/>. Acesso em: 22 nov. 2010.

The Plant List. 2013. The plant list. A working list of all plant species. Disponível em: <http://www.theplantlist.org/>. Acesso em: 22 nov. 2016.

Yamamoto, S. \& E. Nawata. 2009. Use of Capsicum frutescens L. by the Indigenous Peoples of Taiwan and the Batanes Islands. Economic Botany, 63(1): 43-59.

WinklerPrins, A.M.G.A. 2002. House-lot gardens in Santarém, Pará, Brazil: Linking rural with urban. Urban Ecosystems, 6(1-2): 4365.

W3tropicos. Missouri Botanical Garden. Disponível em: <http://www.tropicos.org>. Acesso em: 22 nov. 2016.

Recebido em 17.VII.2016 Aceito em 12.IV.2017 